\title{
Blickdiagnose
}

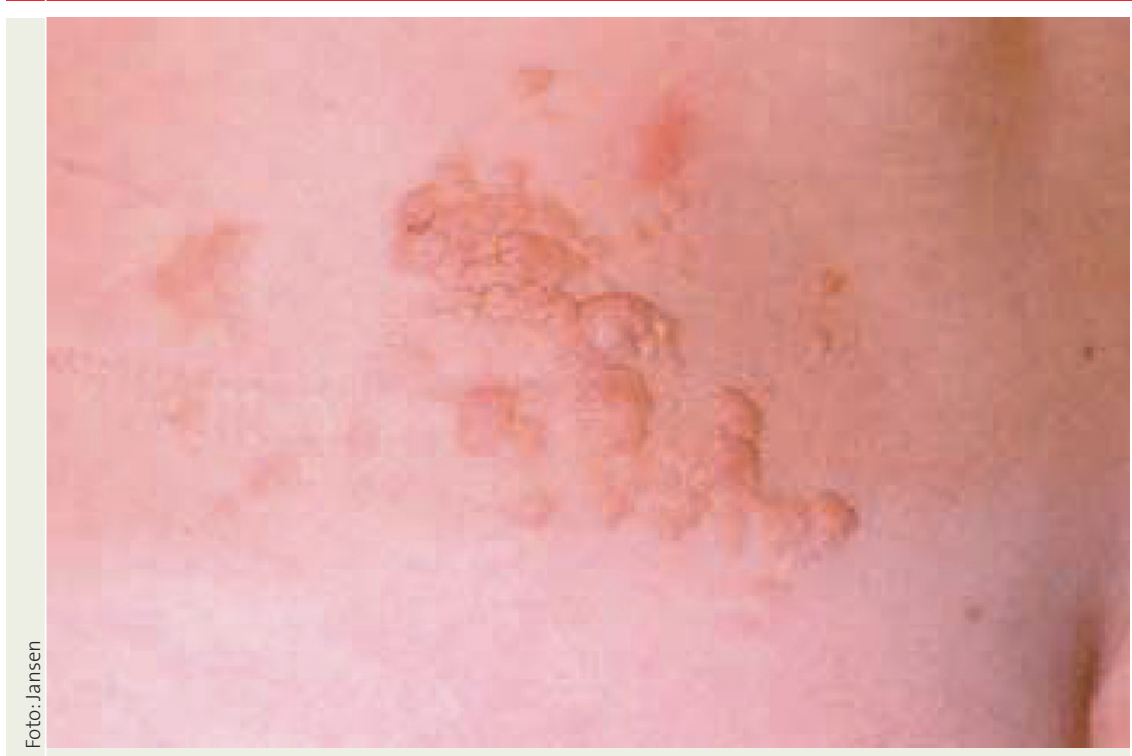

\section{Speck auf den Hüften}

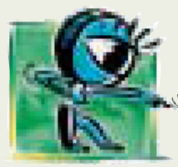

Bei der 16-jährigen, ansonsten gesunden Patientin bestehen von Geburt an Hautveränderungen über der linken Hüfte, die langsam an Größe zunehmen. Abgesehen von einer kosmetischen Beeinträchtigung werden keine anderen Beschwerden angegeben. Bei der klinischen Untersuchung finden sich teils einzeln stehende, teils zusammenfließende, weiche, hautfarbene oder gelbliche, breitbasig aufsitzende, halbkugelig vorgewölbte Papeln und flache Knoten mit glatter oder warzenartiger Oberfläche.

Die Diagnose lautet Naevus lipomatodes cutaneus superficialis (Hoffmann und Zurhelle). Hierbei handelt es sich um eine seltene, benigne, nävoide Fehlbildung mit umschriebener Vermehrung von Fettgewebe, die vor allem beim weiblichen Geschlecht zu beobachten ist. Die Lokalisation in der HüftGlutäal-Becken-Region ist auf die Diagnose hinweisend, ebenso das Bestehen seit Geburt oder früher Kindheit. Klinisch sind Bindegewebsnävi und die fokale dermale Hypoplasie (Goltz-Syndrom) differenzialdiagnostisch abzugrenzen. In Zweifelsfällen lässt sich die klinische Verdachtsdiagnose durch den charakteristischen mikroskopischen Befund sichern.

Als Therapie bei dem nur kosmetisch störenden Nävus kommt im Bedarfsfall eine chirurgische Exzision oder Verbesserung des Hautoberflächenreliefs durch Laserabtragung in Betracht.

- Dr. med. Thomas Jansen, Oberarzt, Klinik und Poliklinik für Dermatologie, Venerologie und Allergologie der Universität Essen, Hufelandstraße 55, D-45122 Essen

Keyword: Naevus lipomatodes cutaneus superficialis

\section{Ihr besonderer Fall?}

Sicher sehen auch Sie ab und an einen besonders eindrucksvollen Befund in Ihrer Praxis. Fotografieren Sie ihn, schreiben Sie uns unter dem Stichwort „Blickdiagnose”, bei Veröffentlichung erhalten Sie 100 Euro.

MMW-Fortschritte der Medizin

E-Mail: manhart@urban-vogel.de

Fax: 089/4372-1420

Weitere interessante Blickdiagnosen finden Sie in unserem Online-Archiv unter www.mmw.de. 